\title{
Direitos humanos no Brasil: aportes para compreensão das ambiguidades $e$ armadilhas persistentes
}

\author{
Human rights in Brazil: contributions \\ to understanding the persistent ambiguities and pitfalls
}

Silene de Moraes Freire*

\begin{abstract}
Resumo - De modo sucinto, o presente artigo objetiva mapear alguns aspectos importantes que permeiam o debate, a defesa e a ativa intervenção no campo dos direitos humanos no Brasil. Recoloca a necessidade de repensar as ambiguidades e armadilhas persistentes geradas por este campo, bem como as possibilidades engendradas pelo tema em tempos de barbárie.

Palavras-chave: direitos humanos; barbárie; neoliberalismo; Brasil

Abstract - Briefly, the present article aims to map some important aspects that permeate the debate, the defense and the active intervention in the field of human rights in Brazil. Replacing the need to rethink the ambiguities and persistent pitfalls generated by it, as well as the possibilities created by the subject in times of barbarism.

Keywords: human rights; barbarity; neoliberalism Brazil.
\end{abstract}

\section{Introdução}

No Brasil, os tempos atuais têm demonstrado que a defesa e o exercício dos direitos humanos ganharam o proscênio da agenda contemporânea. Parece não haver dúvidas de que o debate, a defesa e a ativa intervenção no campo dos direitos humanos assinalam avanços civilizatórios extremamente importantes, mesmo sendo muito desiguais, que precisam de lutas diárias para se manter e serem conquistados. Hoje ativado especialmente na luta pela garantia dos diretos de grupos sociais específicos, o tema dos direitos humanos ainda é pouco aprofundado em termos de significados históricos e possibilidades reais.

Conforme já mencionamos em estudos anteriores, esse tema constitui hoje relevante e disseminada matéria de pesquisa. Inúmeros estudiosos

\footnotetext{
*Pós-doutoranda da ESS da UFRJ. Professora Associada da Faculdade de Serviço Social da Universidade do Estado do Rio de Janeiro (Uerj). Coordenadora do PROEALC/CCS/Uerj. Procientista da Uerj, pesquisadora CNPq, membro da coordenação do Dinter (Uerj/Ufal). Correspondência: Rua São Francisco Xavier, n. 524, sala 8018, bloco E. Maracanã, RJ. CEP: 20550-900. E-mail: <silenefreire@gmail.com>.
} 


\title{
Revista pll pavtg
}

\} DIREITOS HUMANOS NO BRASIL - FREIRE, S. M. \}

das mais variadas correntes de pensamento e filiações políticas têm se debruçado sobre o assunto. No Brasil, por exemplo, a agenda das lutas e defesas dos direitos humanos já conta com um séquito de intelectuais, de diferentes áreas e com distintas temáticas, que abrange desde a luta contra a permanência do trabalho escravo no século XXI, até a defesa das causas indígenas, homossexuais, das mulheres, dos negros, das questões urbanas e rurais etc. Tal movimento tem dificultado ao leitor leigo distinguir, no debate acerca dos direitos humanos, argumentos analíticos de abordagens distintas e até antagônicas, bem como as possibilidades reais que eles engendram em nosso país.

Apesar de a Declaração Universal dos Direitos Humanos, o mais importante marco "universalizador" que coroou a militância dos direitos humanos no pós-Segunda Guerra Mundial, já ter passado dos 60 anos de existência, a disputa política do tema parece longe de ser encerrada. José Damião Trindade (2006), ao resgatar a História social dos direitos humanos, indagou o motivo da expressão direitos humanos ter se tornado tão maleável, complacente e moldável pelos mais inesperados personagens. Para o autor, essa indagação deve ser constante na atualidade.

Segundo Trindade (2006), o uso diferente por "canalhas" e "anjos" estaria exatamente indicando a complexidade deste tema. Para ele, o fato de que diferentes figuras políticas se apropriaram da linguagem dos direitos humanos para respaldar esquemas de ordem social, até mesmo com um caráter ditatorial, colabora para aumentar a complexidade que envolve o debate. Um exemplo verídico foi a trajetória do nazismo na sociedade germânica, tendo como ícone Hitler.

Slavoj Zizek (2010, p. 11), ao escrever o artigo intitulado Contra os Direitos Humanos, também resgatou a necessidade de se pensar rigorosamente o tema, que, para ele, deve ser visto sob forte suspeita na atualidade.

\begin{abstract}
Álibi para intervenções militares, sacralização para a tirania do mercado, base ideológica para o fundamentalismo do politicamente correto: pode a 'ficção simbólica' dos direitos universais ser recuperada com vistas a uma politização progressiva das relações socioeconômicas vigentes? (grifos nossos).
\end{abstract}

Cabe ressaltar que a crítica à concepção abstrata de igualdade e aos direitos humanos já havia sido formulada por Marx (1975) na Questão Judaica. Marx (1975, p. 62) nos advertiu com muito rigor, ao analisar os direitos do homem na França e nos Estados Unidos, para o fato de que a distinção entre os direitos do homem e os direitos do cidadão, em realidade, revelava a separação existente entre o homem real e o cidadão abstrato. Ou seja,

O homem como membro da sociedade civil é identificado como o homem autêntico, o homem como distinto do cidadão, porque é o 


\section{ReVistg all paUtg}

\} DIREITOS HUMANOS NO BRASIL - FREIRE, S. M. \}

homem na sua existência sensível, individual e imediata, ao passo que o homem político é unicamente o homem abstrato, artificial, o homem como pessoa alegórica, moral.

Para Marx (1993, p. 58),

nenhum dos supostos direitos do homem vai além do homem egoísta, do homem enquanto membro da sociedade civil; quer dizer, enquanto indivíduo separado da comunidade, confinado em si próprio, ao seu interesse privado e ao seu capricho pessoal.

O direito burguês se refere a um homem que não pode ser concebido enquanto ser genérico. Não se trata de mera imperfeição de uma elaboração jurídica precária, mas acontece porque a própria sociedade, expressão da vida genérica, aparece como algo externo ao indivíduo, como limitação de sua independência e liberdades originais. "É a preservação da propriedade e das suas pessoas egoístas" que vai manter unida a diversidade de interesses particulares (MARX, 1993, p. 58).

Marx (1991) foi um ferrenho crítico dos limites dos direitos humanos na sociedade burguesa. A questão dos direitos no capitalismo sempre preocupou o autor. Em seus escritos iniciais, Marx (1991) tem como temática a questão do direito, da filosofia e da história. Como registrou Weffort (1996, p. 229), é precisamente esse conjunto de reflexões, datadas entre 1841-1843, que fornece "o roteiro que vai do direito e da filosofia à economia". O mesmo, diz ele, pode ser entendido "também como uma chave do método de Marx e como um critério para localizarmos o sentido que ele atribui à política."

Os direitos humanos de "liberdade", "fraternidade" e "igualdade" são, para Marx, como observa Mészáros (1993, p. 207), problemáticos não por si próprios, mas em função do contexto em que se originam, "enquanto postulados ideais abstratos e irrealizáveis, contrapostos à realidade desconcertante da sociedade de indivíduos egoístas." Melhor dizendo, para Marx, como lembra Mészáros (1993, p. 207), é extremamente complicado acreditar que "uma sociedade regida pelas formas desumanas da competição antagônica e do ganho implacável, aliados à concentração de riquezas e poder em um número cada vez menor de mãos", possa defender os direitos humanos. Não por acaso, Marx (1975, p. 29 - grifos no original) menciona que

os chamados direitos humanos em sua forma autêntica, sob a forma que lhes deram seus descobridores norte-americanos e franceses, [nada mais são que] direitos políticos, direitos que só podem ser exercidos em comunidade com outros homens. Seu conteúdo é a participação na comunidade e, concretamente, na comunidade política, no Estado. Estes direitos se inserem na categoria de liberdade política, na categoria de direito civis, [...]. 


\section{Revista pll pavtg}

\} DIREITOS HUMANOS NO BRASIL - FREIRE, S. M. \}

Marx rejeita enfaticamente a concepção liberal de que "o direito à propriedade privada (posse exclusiva) constitui a base de todos os direitos humanos." (MÉSZÁROS, 1993, p. 208). A emancipação política, para Marx (1991, p. 121), representa uma "revolução parcial", uma "revolução que deixa de pé os pilares do edifício." Isso significa que a sociedade em geral (tanto a classe burguesa, quanto a classe trabalhadora), na busca pela legitimação e regulamentação dos direitos, acaba brindando com entusiasmo as conquistas políticas, que se confundem como interesses de todos. Assim sendo, na ordem capitalista, "somente em nome dos direitos gerais da sociedade pode uma classe especial reivindicar para si a dominação geral." (MARX,1991, p. 122).

Entendemos que não se trata simplesmente de negar ou aceitar acriticamente a questão dos direitos humanos como uma possibilidade de conquistas históricas das classes subalternas, mas de problematizá-la para entender o seu significado real em cada contexto histórico. Nesta direção, concordamos com Netto (2009, p. 9) quando observa que "a defesa dos direitos humanos se fragiliza se não tiver claro que, no mundo contemporâneo, e na América Latina contemporânea, os direitos humanos, ainda que na sua especificidade e irredutibilidade, inscrevem-se no campo dos direitos sociais."

Desse modo, objetivamos suscitar algumas questões que "particularizam" o debate dos direitos humanos no Brasil, com objetivo de ampliarmos o campo de reflexão sobre as verdadeiras possibilidades engendradas pelo tema.

\section{Subsídios para o entendimento dos direitos humanos no Brasil}

A agenda de defesa e garantia dos direitos humanos na América Latina foi tardiamente ativada, podendo ser percebida mais especialmente na luta contra as ditaduras que infernizaram a vida latino-americana. Vale lembrar que o tema da violação dos direitos humanos foi um dos pontos mais importantes da pauta política no período de transição para democracia em diferentes países da região, embora não seja, assim como o tratamento dos conflitos posteriores à liberalização e democratização dos regimes autoritários, tema específico da América Latina. A mesma situação se apresentou em países como Espanha, Portugal e Grécia, quando do final de períodos de autoritarismo que, no caso português e espanhol, duraram mais de três décadas. Entretanto, esta importância foi diferenciada de país para país. O Brasil também fez parte desta luta tardia.

Assim, a defesa dos diretos humanos, em nossa latitude, remete diretamente ao terrorismo de Estado do final do século $X X$, relacionado à questão da Ditadura Militar que dizimou e encarcerou centenas de vidas (dos sujeitos de distintos projetos societários que lutavam por um país demo- 


\section{ReVistg all paUtg}

\} DIREITOS HUMANOS NO BRASIL - FREIRE, S. M.

crático) nos duros e longos 21 anos em que vigorou. No entanto, a questão das violações e a descoberta de uma nova postura na valorização dos direitos humanos não encontrou a mesma força como em outros países. Também evidenciam essa questão diversos países do leste europeu, anteriormente sob a esfera de influência da União Soviética, nos quais novos governos colocam em discussão os atos dos governantes dos regimes preexistentes, inclusive levando a julgamento antigas autoridades. Sobre isso, tratam autores como O'Donnell, Schimitter e Whitehead (1988).

A característica principal do retorno à democracia em nosso país foi a transição "pelo alto". Em se tratando de um país cujos momentos decisivos da sua história foram sempre manobras "pelo alto", o conceito de "revolução passiva" (ou revolução "pelo alto") é extremamente significativo para a compreensão desse processo. (FREIRE, 2011).

Ou seja, o fim do regime autoritário foi viabilizado através de uma "transição negociada para a democracia" (FREIRE, 2011, p.32). Desde metade dos anos 1970, era preparado o processo da "distensão" lenta e gradual para a "abertura". Como observou Freire (2011), as violações mais graves cometidas pela Ditadura Militar no Brasil ocorreram no início dos anos 1970, no Governo Médici, que ficou conhecido como os "anos de chumbo" do regime. Este período foi o mais repressivo da Ditadura Militar, estendendo-se basicamente do fim de 1968, com a edição do Al-5 em 13 de dezembro, até o final do Governo Médici, em março de 1974. Alguns analistas do período reservam a expressão "anos de chumbo" especificamente para o Governo Médici. Entretanto, a linha dura entre os militares foi contida no Governo Geisel (1974-1979), diminuindo e mudando o caráter das formas de repressão.

Um exemplo nesta direção foi a Lei 6.683, denominada Lei da Anistia, criada em meados de 1979. Ela concedeu anistia aos que cometeram "crimes políticos ou conexos com este" (art. 1), excetuando os que foram condenados pela prática de crimes de terrorismos, assalto, sequestro e atentado pessoal" (par. 2). (BRASIL, 1979).

A Lei de Anistia tinha dois objetivos: permitir a reincorporação dos exilados à vida política, para aqueles que foram cassados e presos políticos, e tentar anular, na raiz, qualquer possibilidade de discussão acerca de punições a autoridades envolvidas em atos de terrorismo de Estado tortura, assassinatos etc. (FREIRE, 2011, p. 75). Apesar das inúmeras denúncias realizadas pelos movimentos sociais sobre sequestros, torturas e assassinatos praticados pelos órgãos de repressão, a anistia pactuada não foi nem ampla, nem geral ou irrestrita. Almeida (2004, p. 43) mapeou alguns desses limites:

a) a sua abrangência foi reduzida à época da promulgação da Lei (15 de agosto de 1979), de forma que a Lei da Anistia buscou instituir o sentido de identidade perfeita entre o 'perdão oficial' às práticas prenhes de resistência e lutas e o fim dos atos que o ensejaram; b) a 
interpretação hegemônica, ensejada pela definição de 'crimes conexos', isto é, 'os crimes de qualquer natureza relacionados com crimes políticos ou praticados por motivação política' (art. $1^{\circ}$, par. $1^{\circ}$ ), segundo a qual a Lei abrange a anistia aos torturadores, igualando as práticas de terror do Estado àquelas de resistência a esse terrorismo oficial e institucionalizado - essa interpretação sobrepõe-se, inclusive, ao compromisso internacional assumido pelo Brasil ao ratificar a Convenção Americana de Direitos Humanos, em 1992, que torna imprescritível o crime de tortura.

Somente depois de mais de uma década, quando a Ditadura havia encerrado seu longo ciclo, mais precisamente no dia 4 de dezembro de 1995, a Lei 9.140 declarou, em seu art. 1ํ, legalmente reconhecidas como mortas as pessoas que participaram ou foram acusadas de participação em atividades políticas, no período de 2 de setembro de 1961 a 5 de outubro de 1988, e que, por este motivo, foram detidas por agentes públicos, estando desaparecidas, sem que delas houvesse notícias (BRASIL, 1995, p. 44). A Lei 9.140 traz em anexo uma relação nominal de 136 pessoas e cria uma comissão, com a participação das comissões de familiares, para fazer o levantamento de novos casos não incluídos.

Como mencionou Almeida (2004), a lei reconhece que foram vítimas da repressão todas aquelas pessoas que

por terem sido acusadas de participação, em atividades políticas, tenham falecido por causas não naturais, em dependências policiais ou assemelhadas; 'tenham falecido em virtude de repressão policial sofrida em manifestações públicas ou em conflitos armados com agentes do poder público'; tenham falecido em decorrência de suicídio praticado na iminência de serem presas ou em decorrência de sequelas psicológicas resultantes de atos de tortura praticados por agentes do poder público. (art. 40, inciso I, alíneas b, c, d apud ALMEIDA, 2004, p. 45).

No ano de 2012, o Governo Federal nomeou um grupo de juristas e professores incumbidos de integrar a chamada Comissão da Verdade. Tal comissão visava realizar investigações sobre os vários crimes cometidos pelo Estado brasileiro entre os anos de 1937-1945 e 1964-1985. Nesse recorte temporal, houve interesse especial em buscar os crimes que aconteceram nos dois regimes ditatoriais dos períodos.

Antes da criação da Comissão da Verdade continuava existindo uma discordância entre o governo e alguns grupos de direitos humanos com relação aos encaminhamentos que a lei indicou. Isto porque ela reconhecia as mortes e previa o pagamento de indenização aos familiares, mas alguns grupos consideravam fundamental esclarecer detalhadamente as circunstâncias em que se deram essas mortes, radicalizando as investigações e não focando apenas em um dos lados da questão. Esta seria a relação Estado $X$ vítimas, transformada na relação Estado $X$ familiares das vítimas, 


\section{ReVistg all pavtg}

\} DIREITOS HUMANOS NO BRASIL - FREIRE, S. M.

como tema do campo da responsabilidade civil. Em suma, esse aspecto fazia com que a questão se afastasse do campo do direito público para cair no campo do direito privado.

Segundo Stumpf González (2007, p. 10), a oferta de indenização divorciada da investigação implicava na "transformação da discussão em questão patrimonial - o valor do débito, que uma vez saldado, encerraria a relação." Entendemos que essa lei suscita até hoje alguns pontos controversos.

Utilizados os parâmetros correntes do campo da responsabilidade civil, o que se faz é uma manutenção das distâncias sociais, pois a família do operário receberá uma indenização de padrão operário, a do intelectual, a correspondente a esta posição na sociedade.

No ano de 2007, portanto, antes da criação da Comissão da Verdade, González (2007, p. 8) registrou que,

a transição pactuada afastou da agenda a discussão acerca dos crimes da ditadura no Brasil. Diferentemente da Argentina, não houve uma suspensão das investigações ou limitação de julgamentos. Simplesmente não se permitiu que investigações sérias ocorressem. Incluise aqui também casos posteriores à lei de anistia, como a colocação de uma bomba na sede nacional da $\mathrm{OAB}$ e a explosão do Rio Centro. Por outro lado, esta decisão de 'deixar para traz o passado' não partiu da população, como no plebiscito uruguaio, que mesmo que tenha ocorrido sob pressão, foi uma forma de consulta democrática.

9.140, de 1995,

Na realidade, não se tratava de um problema intrínseco à Lei

mas de uma blindagem das elites às possibilidades de reconstrução e desvendamento de um passado que pulsa insepulto, que, por meio de um pacto pelo alto, negociam a história e clamam pelo seu esquecimento. (ALMEIDA, 2004, p. 45).

Entendemos que somente em 2012, com a Comissão da Verdade, começou a tentativa de recolocar a discussão acerca dos crimes da Ditadura no Brasil. A busca por respostas sobre responsabilidade e circunstâncias das mortes dos perseguidos pela Ditadura, bem como dos torturados e presos sobreviventes, tem sido vista como um direito perseguido pelas vítimas e seus familiares. No entanto, existe um direito do conjunto da população representada pelo Estado que é o de tomar conhecimento sobre esses fatos.

Apesar dos limites da anistia no Brasil, que fez parte do universo da transição inconclusa, em toda América Latina é inegável que o tema, que parecia relegado a um segundo plano, foi novamente trazido à ordem do dia após a estruturação dos novos regimes e a realização de sucessivas eleições presidenciais. Como demonstra Freire (2014, p. 91), 
A abertura de processo contra o General Pinochet e a investigação da Caravana da Morte, no Chile, o processo contra o General Videla, entre outros oficiais, por desaparecimento e tráfico de crianças no período ditatorial, na Argentina, a investigação da Operação Condor, o reconhecimento da morte de militantes políticos desaparecidos e indenização de suas famílias, a Comissão da Verdade no Brasil, não são uma ilustração.

A partir da transição brasileira, os movimentos de defesa de direitos humanos buscam estender sua atuação aos presos comuns. Segundo Caldeira (1991), o discurso é articulado em torno do preso como cidadão, e encontra dificuldades de ser aceito. Para os opositores, o preso político é geralmente um inocente preso por suas ideias; já o preso comum é um criminoso que teria motivos para estar na cadeia. Criou-se, assim, uma imagem de que defender os direitos humanos é defender bandidos. Ela foi construída com a ajuda incondicional da mídia que, no Brasil, é uma das maiores responsáveis pela criminalização dos direitos humanos. ${ }^{1}$

Para Freire (2014), a experiência histórica ensina que a tolerância com as violações aos direitos humanos, dirigida contra alguns grupos específicos, com frequência leva também a atropelos generalizados. Não são poucas as pessoas no Brasil que ainda acreditam na visão dos direitos humanos como um obstáculo na luta contra o delito. Frequentemente escutamos que direitos humanos são direitos de bandidos. Ou, como sempre menciona o militar de reserva e deputado Jair Bolsonaro, reeleito pelo Rio de Janeiro: "direitos humanos apenas para os humanos direitos".

Ainda segundo Freire (2014), quando o enfrentamento da criminalidade é visto como uma guerra, como nos tempos atuais, os defensores dos direitos humanos são tratados quase como traidores, que, por alguma razão, optaram por defender o "inimigo" em vez de proteger o conjunto da sociedade. Ou seja, estão lutando para garantir os direitos de pessoas não "direitas". Não por acaso, muitos acreditam que o extermínio de jovens "suspeitos", as chacinas profiláticas, e outros aviltamentos sofridos diariamente pela população pobre e quase sempre negra, não conflitam frontalmente com a garantia dos direitos humanos. Na percepção dessas pessoas, os supostos delinquentes não fazem parte do coletivo de cidadãos e, portanto, não possuem direito a terem direitos.

Parece inegável reconhecer que os longos anos de ditadura afetaram o exercício da cidadania, gerando uma cultura avessa aos valores humanos. A ditadura brasileira, ao aprofundar a cultura política do autoritarismo, ampliou o leque da negação dos direitos humanos no país. Negados pelas elites, eles emergem para o século XXI através de lutas que revelam os limites da democracia no Brasil. Sem trazer à luz a tortura do

${ }^{1}$ A esse respeito ver: Freire (2009) e Freire e Carvalho $(2007 ; 2008)$. 


\section{AeVistg all paUtg}

\} DIREITOS HUMANOS NO BRASIL - FREIRE, S. M. \}

passado, passaremos longe de banir de vez a tortura como prática dos agentes estatais brasileiros e de aprofundar a democracia em nosso país.

A realidade brasileira tem demonstrado grandes dificuldades de efetivação dos direitos humanos. Contudo, também não podemos negar o avanço obtido com o processo de redemocratização, que culminou na Constituição de 1988, considerada o marco na positivação dos direitos humanos. Segundo Ferreira Filho (2006, p. 99),

todas as Constituições, sem exceção, enunciaram Declarações de Direitos. As duas primeiras contentaram-se com as liberdades públicas, vistas claramente como limitações ao Poder. Todas, a partir de 1934, a estas acrescentaram, na Ordem Econômica, os direitos sociais. A atual prevê pelo menos um dos direitos de solidariedade.

Na mesma direção, Silva (2006, p. 170) lembra que foi a Constituição Federal de 1988, ainda em vigor, que conferiu a primazia dos direitos humanos ao declará-los principalmente nos Títulos I - Dos Princípios Fundamentais - e II - Dos Direitos e Garantias Fundamentais, antecedendo a estruturação do Estado. Apenas por questões de registro, é importante destacar que "a primeira constituição no mundo a subjetivar e positivar os direitos do homem, dando-Ihes concreção jurídica efetiva, foi a do Império do Brasil, de 1824, anterior, portanto, a da Bélgica de 1831" (SILVA, 2006, p. 172), a que se tem dado maior destaque. No entanto, só com a Carta Constitucional de 1988 foi atribuída a "primazia" aos direitos humanos no BrasilContudo, se a Constituição de 1988 afirmou - com a maior centralidade de nossa história - a primazia dos direitos humanos, a realidade a negou. $\mathrm{Na}$ atualidade, a luta em defesa e pela garantia desses direitos se tornou um campo de tentativa de proteção e denúncia contra a situação de barbárie que vivemos.

\section{Direitos humanos no contexto da barbárie neoliberal}

Quando pensamos os efeitos perversos do neoliberalismo, aprofundados a partir do final do século XX, por exemplo, não podemos esquecer que entre nós eles se apresentam como o caldeamento de uma arraigada sociabilidade autoritária na nossa sociedade, com os processos de mundialização. O que não significa ignorar que, nos locais onde tal sociabilidade foi menos autoritária, o neoliberalismo também não tenha sido portador de um altíssimo grau de letalidade social. Cabe lembrar que vivemos num país que tem apenas lapsos democráticos, pois ainda não superou os fortes vieses autoritários, marcas de experiências de uma cultura política autoritária ${ }^{2}$.

${ }^{2}$ A esse respeito, ver: Silene Freire (2011). 


\section{Revista pll pavtg}

\} DIREITOS HUMANOS NO BRASIL - FREIRE, S. M. \}

Houve uma sequência do capitalismo autoritário nas ondas da modernização conservadora brasileira, conforme mencionou Wernekc Vianna (2009). Para esse autor, vivenciamos hoje, não por acaso em pleno contexto neoliberal, uma política social sem política que convida para um festim do consumo, a gala do mercado consumidor. É como se a história do Brasil estivesse se completando diante dos nossos olhos, num processo de pacificação final em que a "questão social" é enfrentada com estratégias derivadas dos militares. A "questão social" passou a ser tratada em termos políticos militares e não na sua capacidade de criar sujeitos de direitos.

Nessa direção, Wernekc Vianna (2009, p. 52) pede licença para sair do senso comum e adverte para os perigos da penalização da república, que vem fazendo com que o código penal ameace se tornar um dos instrumentos principais da vida republicana brasileira. Para o autor, "esse entendimento é responsável inclusive, pela conversão da arena política, numa enorme arena judiciária." Segundo ele, "a mídia, a Polícia Federal e o Ministério Público hoje atuam juntos e significam uma presença explosiva na vida republicana brasileira." (VIANNA, 2009, p. 53). Não é pouco frequente que a percepção de alguns casos mais evidentes e que mais mobilizam a opinião pública decorram da articulação dos três: mídia, Polícia Federal e Ministério Público.

Segundo Zaffaroni (2011), a produção midiática daquilo que Chomsky chamou de aquiescência passiva e manufatura do consentimento, é realizada milimetricamente; palavras são escolhidas e a elite é sempre colocada como vítima. Para o autor, os especialistas usados pela mídia são sempre os mesmos para referendar essa manufatura do consentimento, verdadeira colonização das almas. Colonização esta que, como mencionou Vera Batista (2011, p. 9), fez com que "passássemos da crítica da truculência e da militarização da segurança pública à sua naturalização e agora ao aplauso, adesão subjetiva à barbárie." Triunfalismo exorbitante da hegemonia neoliberal.

Cabe ressaltar que não atribuímos ao termo barbárie o mesmo sentido que aquele reproduzido pelo discurso midiático, ou seja, referido exclusivamente às inseguranças das elites. Barbárie relaciona-se com as forças destrutivas acionadas em determinada sociedade para realização de projetos excludentes de civilização. A valorização do capital determina um crescente aumento de destruição, gerando um contingente populacional destituído de meios de sobrevivência e todas as consequências sociais originadas desta demanda.

Para Marx e Engels (1998) o modo burguês de produção dependeria de crises periódicas para sobreviver, o que implica em regressões momentâneas de civilização. Assim, a relação entre crise no capitalismo e barbárie não é um fenômeno particular. A destruição das forças produtivas é uma necessidade cíclica do processo de valorização e acumulação do capital, como enunciado no Manifesto Comunista: 


\section{ReVistg all paUtg}

\} DIREITOS HUMANOS NO BRASIL - FREIRE, S. M. \}

Nas crises evidencia-se uma epidemia social que teria parecido um contrassenso a todas as épocas anteriores - a epidemia de superprodução. A sociedade vê-se de repente reconduzida a um estado de momentânea barbárie; dir-se-ia que uma fome ou uma guerra de destruição generalizada lhe cortam todos os meios de subsistência; a indústria e o comércio parecem aniquilados. E por quê? Porque a sociedade possui civilização em excesso, meios de subsistência em excesso, indústria em excesso, comércio em excesso. (MARX; ENGELS, 1998, p. 11-12).

Como registrou Menegat (2006, p. 33-34), a barbárie ganha funcionalidade no atual estágio de desenvolvimento do capitalismo. Desde 1929, busca-se driblar os momentos de forte crise econômica, diluindo seus efeitos de destruição no tempo. As crises agora se operam de maneira constante e em várias direções, elevando a sobrevivência ao ideal de cidadania.

O desemprego estrutural é a face mais visível desse processo, na medida em que priva milhões de pessoas do mercado de trabalho, sem perspectiva de retorno. $\mathrm{O}$ aumento do trabalho morto em razão do progresso tecnológico das indústrias faz com que outras formas de violência, para além da destruição das forças produtivas, sejam executadas. A administração do crescente exército industrial de reserva, cada vez com menor aspiração de integrar o "mundo do trabalho", depende da ampliação do sistema punitivo.

É importante mencionar que o paradigma bélico para a Segurança Pública é um artefato, uma construção política através da qual o capitalismo contemporâneo controla os excessos reais e imaginários dos contingentes humanos que não estão no fulcro do poder do capital financeiro. Para que essa construção política adquira o consentimento de que necessita, faz-se mister naturalizar a barbárie.

Essa naturalização da barbárie a que temos assistido se dá no momento da história brasileira em que mais se avança, em termos legais, no debate dos direitos humanos, qual seja: o contexto neoliberal. Só que esses avanços são isolados dos suportes necessários para sua efetivação. Em realidade, eles engendraram ainda mais as ambiguidades e armadilhas do tema.

Nesta direção, é importante lembrar que, no governo do presidente Fernando Henrique Cardoso, em 1996, foi implantado o primeiro Programa Nacional dos Direitos Humanos (PNDH). O Programa representou uma importante abertura à valorização dos direitos humanos na implementação de políticas sociais. Segundo o texto do próprio PNDH, sem abdicar de uma compreensão integral e indissociável dos direitos humanos, o Programa atribui maior ênfase aos direitos civis, ou seja, os que ferem mais diretamente a integridade física e o espaço de cidadania de cada um. O texto apresentado pelo PNDH está diretamente articulado com os princípios da Declaração Universal dos Direitos Humanos. 


\section{Revista pll pavtg}

\} DIREITOS HUMANOS NO BRASIL - FREIRE, S. M. \}

O projeto político, social e econômico do primeiro governo de Fernando Henrique Cardoso evidenciou que o compromisso era com a garantia dos direitos individuais e com a abertura ao "livre mercado". Isso também explica o fato de a proposta do PNDH defender a garantia dos direitos civis em detrimento dos direitos sociais e políticos.

As opções do governo estavam em plena conexão com os rumos do novo regime mundial de acumulação do capital, que alterou, de modo específico, o funcionamento do capitalismo. Como destaca Netto (1999, p. 77),

no Brasil, criavam-se mecanismos políticos-democráticos de regulação da dinâmica do capitalista, no espaço mundial tais mecanismos perdiam vigência e tendiam a ser substituídos, com a legitimação oferecida pela ideologia neoliberal, pela desregulamentação, pela flexibilização e pela privatização - elementos inerentes à mundialização (globalização) operada sob comando do grande capital.

É neste contexto de nítida opção pelos ajustes neoliberais que o Governo FHC acaba por inviabilizar a plena efetivação da Constituição de 1988. Ao ressignificar o papel do Estado, tirando sua responsabilidade sobre a garantia dos direitos sociais, o governo aprofunda ainda mais os limites para a efetivação da "universalização" dos direitos. Em outras palavras, temos um avanço legal dos direitos humanos no mesmo momento em que se limita a plena viabilização da Constituição.

No segundo Governo FHC (1999-2002), o PNDH sofreu uma revisão, passando a destacar os direitos sociais e culturais no processo de "promoção e proteção dos direitos humanos." Tal revisão buscou atender à reivindicação de movimentos da sociedade civil por ocasião da IV Conferência Nacional de Direitos Humanos, realizada em 13 e 14 de maio de 1999, na Câmara dos Deputados, em Brasília (BRASIL, 2002).

Com um período delimitado entre os anos 2002 e 2007, o Segundo PNDH buscou ampliar a esfera das ações governamentais com o objetivo de

apoiar a formulação, a implementação e a avaliação de políticas e ações sociais para a redução das desigualdades econômicas, sociais e culturais existentes no país, visando à plena realização do direito ao desenvolvimento e conferindo prioridade às necessidades dos grupos socialmente vulneráveis. (BRASIL, 2002).

O Segundo PNDH, que começou a vigorar no final do segundo Governo FHC, continuou em vigência no governo de Luiz Inácio Lula da Silva. O PNDH II manteve a lógica desta tirada de responsabilidade do Estado e a agenda neoliberal foi incorporada como proposta de governo, efetivando, em nome do "crescimento econômico", um campo fértil para o mercado financeiro. No Terceiro PNDH, criado em 2010 (BRASIL, 2010) no finalzinho do segundo Governo Lula, o tema da interação democrática entre Estado e Sociedade Civil abre o Programa, de acordo com a ideia de 


\section{ReVistg all paUtg}

\} DIREITOS HUMANOS NO BRASIL - FREIRE, S. M.

que os agentes públicos e todos os cidadãos são responsáveis pela consolidação dos Direitos Humanos no País. O PNDH III propõe a integração e o aprimoramento dos fóruns de participação existentes, bem como a criação de novos espaços e mecanismos institucionais de interação e acompanhamento, como o fortalecimento da democracia participativa. O Programa incluiu também novas questões sobre os direitos humanos, sobretudo ligadas às diversidades e a questão da violência e segurança pública. $\mathrm{O}$ programa foi alvo de muitas tensões, sobretudo dos militares frente à instituição da Comissão Nacional da Verdade. Para solucionar a tensão instalada entre setores militares em razão do PNDH III, foi suprimido do texto assinado pelo presidente Lula o trecho que dizia que a Comissão da Verdade iria promover a apuração das "violações de Direitos Humanos praticadas no contexto da repressão política", que constava no decreto publicado no Diário Oficial de 22 de dezembro. O novo texto aprovado diz apenas que a Comissão deverá "examinar as violações dos Direitos Humanos praticadas" no período de 18 de setembro de 1946 a 5 de outubro de 1988. Não podemos negar a existência de alguns avanços no PNDH III, mas ele não rompeu com a lógica neoliberal dos Programas anteriores e não teve todas as suas propostas efetivadas.

Entretanto, seria um erro negar algumas diferenças que os dois Governos Lula e, mais recentemente, o Governo Dilma construíram com relação aos dois Governos FHC. Distinto dos Governos FHC, que realizaram vários cortes de recursos para os programas sociais (NETTO, 1999), os Governos Lula e o primeiro Governo Dilma focalizaram nas políticas compensatórias e seletivas (vide a implementação e o exacerbado crescimento do Programa Bolsa Família, assim como a criação de novos programas sociais de mesmo cunho).

As alternativas às "novas" expressões da questão social têm sido as políticas voltadas para a pobreza, muitas delas ancoradas na defesa dos direitos humanos. Entretanto, tais políticas apenas confirmam e legitimam a "subalternatização" de vastos segmentos por meio de benefícios que não constituem legítima apropriação dos resultados da economia. "São apenas débito a fundo perdido, preço a pagar pela sustentação de uma economia cuja dinâmica bane e descarta parcelas da população." (NETTO, 1999, p.77)

Concordamos com Maria Carmelita Yazbek (2001, p. 37) quando ela menciona que, com essas "políticas ad hoc, casuísticas, fragmentadas, sem regras estáveis e operando em redes obsoletas e deterioradas, corremos um risco de grave regressão de direitos sociais." Tal regressão implica também na regressão dos direitos humanos.

Podemos dizer que todas as ações governamentais dos governos (neo)liberais pós-Constituição de 1988 só aprofundaram os limites para a efetivação da "universalização" dos direitos no Brasil. 


\section{Revista pll pavtg}

\} DIREITOS HUMANOS NO BRASIL - FREIRE, S. M. \}

Nos governos neoliberais, observamos uma clara tendência de deslocamento das ações governamentais públicas - de abrangência universal - no trato das necessidades sociais em favor de sua privatização.

Esse deslocamento da satisfação de necessidades da esfera do direito público para o direito privado ocorre em detrimento das lutas e de conquistas sociais e políticas extensivas a todos. É exatamente o legado de direitos conquistados nos últimos séculos que foram desmontados nos governos de orientação (neo)liberal, em uma nítida regressão da cidadania que tende a ser reduzida às dimensões civil e política, erodindo a cidadania social. (IAMAMOTO, 2001, p. 75).

\section{Considerações finais}

Em verdade, a história só surpreende aos que de história nada entendem. Há os que a ignoram, e outros que a temem. (Karl Marx)

A Declaração Universal dos Direitos Humanos, em seu artigo 30, assegura que "nada poderá suprimir nenhum dos direitos presentes na Declaração." (ONU, 2000). Mas alguém poderia observar: a Declaração proclama, a realidade trai. O mesmo se pode dizer da nossa Constituição de 1988, cujo valor simbólico foi muito maior que a sua efetivação, já que a realidade brasileira se divorciou dessa possibilidade. Mais uma vez a história confirmou que a declaração formal dos direitos está longe de garantir sua efetivação. Sobretudo quando a hegemonia (neo)liberal reforça, por meio das políticas sociais, a ideia de que indivíduos e pequenos grupos são os únicos responsáveis pela garantia de seus direitos e não dependem do Estado e da sua atividade pública. Outra vez a história demonstra que os indivíduos não nascem com direitos; os direitos são fenômenos sociais, são resultados da própria história.

Liberdade é a palavra que mais se repete nos 30 artigos da Declaração Universal dos Direitos Humanos (ONU, 2000). No artigo 23, a liberdade de trabalhar, ganhar um salário justo e fundar sindicatos está garantida. No entanto, são cada vez mais numerosos os trabalhadores que não têm, hoje, a possibilidade de um trabalho assalariado. A liberdade apregoada pelo (neo)liberalismo é a de participar do mercado. A concepção de "incluído" que guia tal proposta

não é o cidadão portador de direitos civis, políticos e sociais; é o produtor/ consumidor de mercadorias, ainda que a mercadoria seja pipoca. A marca da inclusão deixa de ser a carteira de trabalho e passa a ser o CPF que habilita o indivíduo a transitar numa instituição bancária, ainda que seja num banco só para pobres. (VIANNA, 2007, p. 16). 


\section{ReVistg all paUtg}

\} DIREITOS HUMANOS NO BRASIL - FREIRE, S. M. \}

De acordo com Marilena Chauí (2006, p. 112), dois aspectos merecem destaque na Declaração de 1948. O primeiro é a ambiguidade da (in)definição da propriedade privada como direito. O segundo é que,

afinal, se trata de uma declaração de direitos civis, pois, embora se refira a direitos universais da pessoa humana, seu pressuposto é o da existência de poderes públicos que possam garanti-los, de sorte que os pressupostos da garantia política ou estatal dos direitos humanos o transformam em direitos civis.

Em suma, a busca pela efetivação tardia dos direitos humanos no Brasil, sobretudo representada pela Constituição de 1988, não logrou êxito. Dando continuidade às históricas ambiguidades do tema dos direitos humanos, já denunciadas por Marx ela promoveu uma série de contradições e acabou vítima de muitas armadilhas. Frente à avalanche neoliberal à qual foi submetida pelos governos mencionados, não conseguiu sobreviver imune.

É indiscutível que, no contexto da sociedade burguesa, os direitos humanos se afirmam a partir da universalidade. Entretanto, a universalidade que propõem "esbarra em limites estruturais da sociedade capitalista: uma sociedade que se reproduz através de divisões (do trabalho, de classes, do conhecimento, da posse privada dos meios de produção, da riqueza socialmente produzida." (BARROCO, 2003, p. 11).

O momento que vivenciamos, no Brasil, representa uma situação histórica de diferentes aprofundamentos de abismos:

entre a desigualdade e a liberdade, entre a riqueza e a pobreza, que atingem níveis nunca vistos: a miséria de milhares em favor da riqueza de poucos; logo, uma situação de perda relativa de conquistas no campo dos Direitos Humanos, assim caracterizada. (BARROCO, 2003, p. 11).

O Brasil do início da segunda década do século XXI comprova mais uma vez que, no terreno da história, nada é absolutamente novo. Como observou Mauro lasi (2013, p. 1):

A explosão social que abalou o país em 2013 brotou do terreno escondido das contradições. La para onde se costuma exilar as contradições incômodas: a miséria, a dissidência, a alteridade, a feiura, a violência. Germinaram no terreno do invisível, escondido e escamoteado pela neblina ideológica e o marketingcosmético que epidermicamente encobre a carne pobre da ordem capitalista com grossas camadas de justificativa hipócrita, de cinismo laudatório de uma sociabilidade moribunda.

A partir desta "explosão social", também assistimos a uma onda de conservadorismo abissal que parece ter sido aprofundada em 2014. Tal 


\section{Revista pll pavtg}

\} DIREITOS HUMANOS NO BRASIL - FREIRE, S. M. \}

onda ampliou a legitimidade das chamadas políticas de Segurança Pública, dando suporte para as ações violentas do Estado. Aliás, o desmonte do Estado de Bem-estar Social veio acompanhado da acintosa defesa do Estado Penal. Mesmo que não tenhamos consolidado um Estado de Bem-estar Social, a defesa do Estado Penal também foi aprofundada em nossa latitude.

Hoje, como mencionou Mondaini (2008), dentre os que desconfiam da agenda dos direitos humanos, estão também os neoliberais, que a veem como um fardo a atrapalhar os seus objetivos de lucro racional. $\mathrm{O}$ curioso no Brasil é que a pauta dos direitos humanos e sua incorporação em 1996, através do primeiro Programa Nacional dos Direitos Humanos $(\mathrm{PNDH})$, no Governo FHC, objetivou importante abertura à valorização na implementação de políticas sociais. Isto justamente num contexto conhecido como de desastre social, promovido pela avalanche neoliberal (SOARES, 2003).

Contudo, as críticas à possibilidade de efetivação dos direitos humanos não podem negar que as lutas por eles possibilitam afirmar a importância da resistência em face do avanço das diversas formas de desumanização a que temos assistido. Elas também são capazes de fortalecer ações de denúncia sobre violações e aviltamentos contra a dignidade humana e dar visibilidade a práticas voltadas para o reconhecimento social de muitos seguimentos oprimidos.

Todas essas lutas não cabem nos limites do capitalismo e constituem o que Gramsci (apud FREIRE, 2011, p.14) definiu como guerra de posição. Portanto, mesmo como ilusão construída pelas recentes legalidades, os direitos humanos, como agenda das lutas, podem ser capazes de construir possibilidades históricas de mudança. O estatuto jurídico que ampara os direitos humanos é frágil porque é constrangido por relações sociais que estruturalmente atentam contra esses direitos.

Para além do seu sentido e significado próprios, a luta pelos direitos humanos permitiu e possibilitou - e permite e possibilita - a unidade político-prática de correntes de pensamento e ação que, mesmo diferentes em muitos e decisivos aspectos, colocam seu empenho no valor máximo do humanismo. Em tempos de barbárie, essa questão se tornou ainda mais importante.

Por fim, não podemos esquecer que, na contemporaneidade, a defesa dos direitos humanos não é factível se for autônoma aos direitos sociais. Como José Paulo Netto (2009, p. 9) registrou: "hoje, os direitos humanos são uma face dos direitos sociais."

Por isso, não podemos nos restringir à visão de que os direitos humanos são os direitos civis e políticos que o liberalismo enfatizou, ainda que os limites do capitalismo não os reconheçam plenamente. Ignorar essa questão, dissociando os direitos humanos dos direitos sociais, é aprofundar ainda mais as históricas armadilhas engendradas pelo tema. 


\section{ReVistg all paUtg}

\} DIREITOS HUMANOS NO BRASIL - FREIRE, S. M. \}

\section{Referências}

ALMEIDA, S. S. de. Violência e Direitos Humanos no Brasil. Revista Praia Vermelha, Rio de Janeiro, v. 11, n. 1 set. 2004.

BARROCO, M. L. S. Direitos Humanos e desigualdade. In: As novas faces da barbárie capitalista: desigualdade se combate com direitos. Brasília: CFESS. 2003.

BATISTA, V. M. O Alemão é muito mais complexo. 2011 (mimeo).

BRASIL, Presidência da República. Programa Nacional de Direitos Humanos. Ministério da Justiça, Brasília, 1996. Disponível em: <http://www. direitoshumanos.usp.br/index.php/Direitos-Humanos-no-Brasil/i-programanacional-de-direitos-humanos-pndh-1996.html>. Acesso em: 11 de outubro.

- Ministério da Justiça. Programa Nacional de Direitos Humanos. Brasília, 2002. Disponível em: <http://www.dhnet.org.br/dados/pp/pndh/ pndh_concluido/index.html>. Acesso em: 16 nov. 2010.

- Ministério da Justiça/Governo Federal/Secretaria de Estado de Direitos Humanos. Brasília. 2010. Disponível em: <http://portal.mj.gov.br/ sedh/pndh3/index.html>. Acesso em: 11 nov. 2014.

. Lei no 6.683, de 28 de agosto de 1979. Brasília, 1979.

. Lei no 9.140, de 04 de dezembro de 1995. Brasília, 1995.

CALDEIRA, T.P.R. Direitos humanos ou "privilégio de bandidos?" - Desventuras da democratização brasileira. Novos Estudos CEBRAP, São Paulo, n. 30, jul. 1991.

CHAUÍ, M. Direitos humanos e medo. In: Direitos Humanos e.... São Paulo: Comissão de Justiça e Paz/Editora Brasiliense. 1989.

. Simulacro e Poder: uma análise da Mídia. São Paulo, Editora Fundação Perseu Abramo, 2006.

FERREIRA FILHO, M. G. Direitos humanos fundamentais. São Paulo: Saraiva. 2006.

FREIRE, S.M. (Org.). Direitos humanos e questão social na América Latina. Rio de Janeiro: Gramma. 2009.

. Cultura política, "questão social" e ditadura militar no Brasil: o simulacro do pensamento político de militares e tecnocratas no pós-1964. Rio de Janeiro: Gramma. 2011.

. (Org.). Direitos humanos para quem? Contextos, contradições e consensos. Rio de Janeiro: Editora Gramma. 2014. 


\section{Revista pll pavtg}

\} DIREITOS HUMANOS NO BRASIL - FREIRE, S. M. \}

FREIRE, S. de M.; CARVALHO, A. Midiatização da violência: os labirintos da construção do consenso. Revista Eletrônica Textos e Contextos, v. 7, n. 1, jan./jun. 2008.

. A Construção do "nós" e do "eles" no simulacro da violência do discurso midiático. In: FREIRE, S.M. Direitos humanos: violência e pobreza na América Latina contemporânea. Rio de Janeiro: Letra e Imagem. 2007. GONZÁLEZ, R. S. Direitos Humanos na América Latina hoje: heranças de transições inconclusas. 2007. Disponível em: <http://www.direitos.org.br/ >. Acessado em: 23 abr. 2010.

IAMAMOTO, M. V. A questão social no capitalismo. Temporalis, Brasília, n. 3, ano 2. 2001.

IASI, M. Pode ser a gota d'água. Enfrentar a direita avançando a luta socialista. 2013. Disponível em: <http://tita-ferreira.tumblr.com/post/54052271442/ pode-ser-a-gota-dagua-enfrentar-a-direita-avancando-a>. Acesso em: 23 dez. 2013.

MARX, K. A questão judaica. Rio de Janeiro: Achiamé. 1975.

- Introdução à crítica da filosofia do direito de Hegel. São Paulo: Moraes. 1991.

. Terceiro manuscrito. In: Manuscritos econômicos e filosóficos. Lisboa: Edições 70. 1993.

MARX, K.; ENGELS, F. Manifesto do Partido Comunista. São Paulo: Cortez. 1998.

MENEGAT, M. O olho da barbárie. São Paulo: Expressão Popular. 2006.

MÉSZÁROS, I. Marxismo e direitos humanos. In: Filosofia, ideologia e ciência social: ensaios de negação e afirmação. São Paulo: Ensaio. 1993.

MONDAINI, M. Direitos humanos. São Paulo: Contexto. 2008.

NETTO, J.P. FHC e a política social: um desastre para as massas trabalhadoras. In: LESBAUPIN, I. (Org.). O desmonte da nação: balanço do governo FHC. Petrópolis: Vozes. 1999.

- Democracia e direitos humanos na América Latina. In: FREIRE, S. de M. (Org.). Direitos humanos e questão social na América Latina. Rio de Janeiro: Gramma. 2009.

O'DONNELL, G.; SCHIMITTER, P. C.; WHITEHEAD, L. Transições do regime autoritário - Sul da Europa. São Paulo: Vértice. 1988.

ONU. Declaração Universal dos Direitos do Homem. Rio de Janeiro: UNIC. 2000.

SILVA. J.A. Curso de Direito Constitucional Positivo. São Paulo: Malheiros. 2006. 


\section{heVista pll pavtg}

\} DIREITOS HUMANOS NO BRASIL - FREIRE, S. M.

SOARES, L.T.R. O desastre social: os porquês da desordem mundial. Rio de Janeiro: Record. 2003.

YAZBECK, M.C. Pobreza e exclusão social: expressões da questão social no Brasil. Temporalis, Brasília, n. 3, ano 2. 2001.

WACQUANT, L. Punir os pobres: a nova gestão da miséria nos Estados Unidos. Rio de Janeiro: F. Bastos. 2001.

WEFFORT, F. Marx: a política e revolução. In: Os clássicos da política. São Paulo: Ática. 1996.

VIANNA, M.L.W. Constatação perturbadora. Rio de Janeiro, Jornal da UFRJ, maio 2007.

. Hiper-realidade ou hipoteoria? Disponível em: <http://www.aces sa.com/gramsci/?page=visualizar\&id=764>. Acesso em: 2007

VIANNA, L.W. A crise e a realidade política. Estudos Avançados (USP), São Paulo, v. 23, n. 67. 2009.

TRINDADE, J.D.L. História social dos direitos humanos. São Paulo: Petrópolis. 2006.

ZAFFARONI, E.R. La palabra de los muertos: conferencias de criminologia cautelar. Buenos Aires: Ediar. 2011.

ZIZEK, S. Contra os direitos humanos. Mediações, Londrina, v. 15, n. 1, jan/jun. 2010.

Recebido em 11 de novembro de 2014.

Aprovado para publicação em 25 de novembro de 2014. 


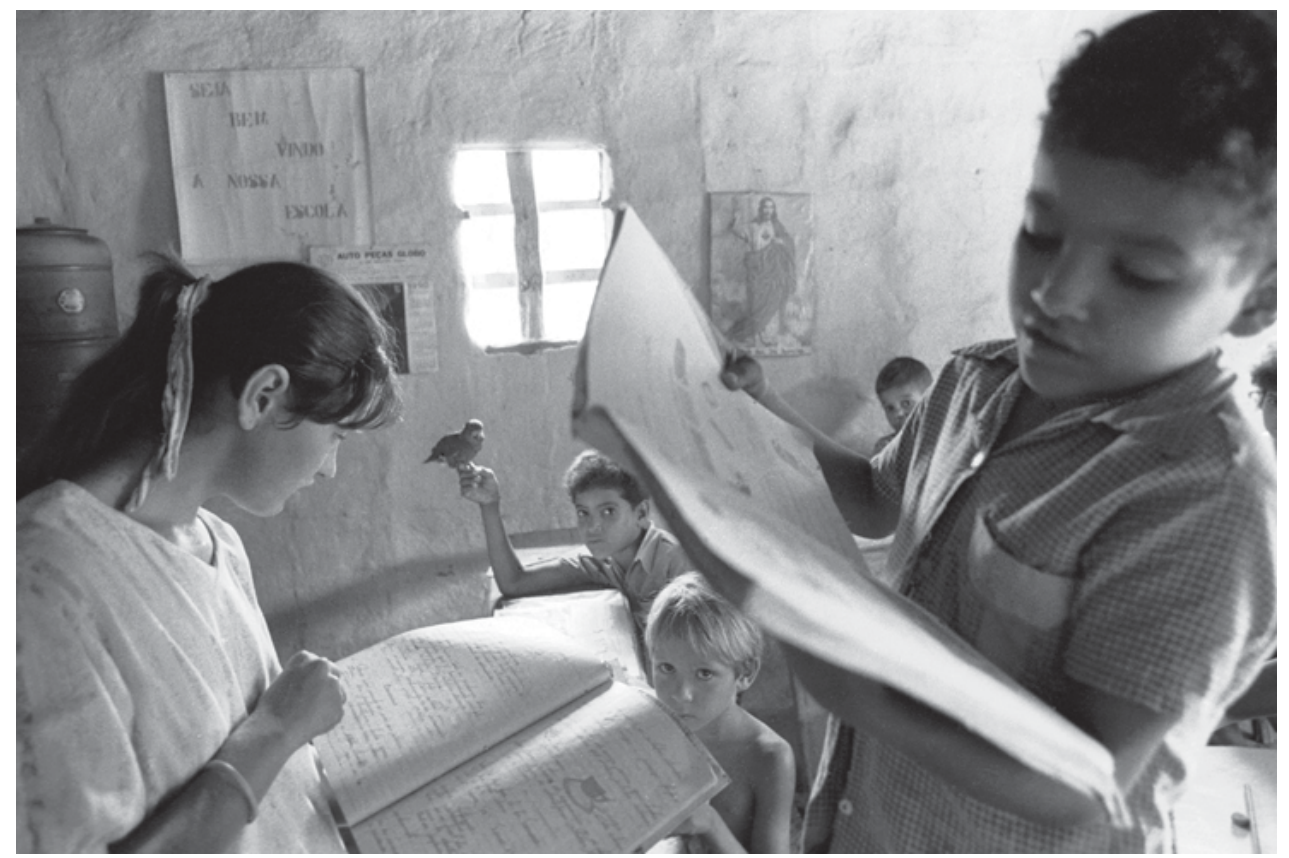

Fotografias: João Roberto Ripper 